\title{
Southern Europe a
}

Mariapaola D’Imperio, Barbara Gili Fivela, Mary Baltazani, Brechtje Post, and Alexandra Vella

The Oxford Handbook of Language Prosody

Edited by Carlos Gussenhoven and Aoju Chen

Print Publication Date: Dec 2020 Subject: Linguistics, Phonetics and Phonology

Online Publication Date: Feb 2021 DOI: 10.1093/oxfordhb/9780198832232.013.15

\section{Abstract and Keywords}

This chapter reviews the prosodic systems and intonational phonology of a group of Southern European languages: Italian, French, Greek, and Maltese. It describes their stress, phrasing, rhythm, and intonational phonology, with particular attention to phonologically informed experimental work. In the case of Italian, given the lack of a spoken standard (which is only used by professional speakers) and the descriptions of quite a number of varieties (e.g. Bari, Florence, Naples, Palermo, Pisa, and Rome, inter alia), this review highlights common prosodic and phrasing features first, and subsequently covers any definable variety-specific intonational features. For French, the survey focuses on hexagonal French, while Athenian Greek is the representative variety for Greek, with some excursions into regional varieties. For Maltese, the chapter only focuses on its standard.

Keywords: Southern Europe, intonational phonology, laboratory phonology, rhythm, prosodic systemss, Italian varietiess, Frenchs, Malteses, Greek

\subsection{Introduction}

THIS chapter reviews the prosodic systems and intonational phonology of a group of Southern European languages: Italian, Greek, Maltese, and French. It describes their stress, phrasing, rhythm, and intonational phonology, with particular attention to phonologically informed experimental work. In the case of Italian, given the lack of a spoken standard (only used by professional speakers) and the descriptions of quite a number of varieties (e.g. Bari, Florence, Naples, Palermo, Pisa, and Rome, inter alia), our review highlights common prosodic and phrasing features first, and subsequently covers varietyspecific intonational features. For French, the survey focuses on hexagonal French, while Athenian Greek is the representative variety for Greek, with some excursions into regional varieties. Standard Maltese is the variety of this language dealt with here. 


\subsection{Prosodic structure}

This section surveys the available descriptions of stress, rhythm, and prosodic constituency. ${ }^{1}$ Italian, French, and Greek are among the languages that helped to shape the Prosodic Phonology framework of the 1980s (Selkirk 1984; Nespor and Vogel 1986). They all have stress accent, with differences among them in the location, assignment, and behaviour of lexical stress.

\section{(p. 237) 16.2.1 Stress}

In Italian, lexical stress is by default on the penultimate syllable (D'Imperio and Rosenthal 1999), for 80\% of trisyllabic words (Thornton et al. 1997; Sulpizio and McQueen 2012). Antepenultimate and final stress occur in $18 \%$ and $2 \%$ of trisyllabic words, respectively, as in (1a) (Thornton et al. 1997), while earlier stress positions occur in quadrisyllabic or longer words, mostly in the verbal system through derivation, as in (1b), from D'Imperio and Rosenthal (1999).

\section{a. 'fatele 'do them!' /'fatele/ \\ b. 'fatevele 'do them yourselves' /'fatevele/}

Trochaic vowel lengthening occurs in open penultimate (but not antepenultimate or final) syllables (see van Santen and D'Imperio 1999). Moreover, in long, generally complex words, earlier studies proposed a potential secondary stress (Bertinetto 1980; Nespor and Vogel 1986; e.g. normalmente 'generally' /,normal'mente/), as a docking site for a (prenuclear) pitch accent in double-accented words. Unstressed syllables are usually shorter than stressed ones (Avesani et al. 2007); their vowels are reduced to schwa in some southern varieties (Rohlfs 1966) and may be subject to resyllabification as part of a weakening process in some more northern varieties ${ }^{2}$ (e.g. plast[ik]a $\rightarrow$ plast[ix]a $\rightarrow$ plast[i]a $\rightarrow$ plast[j]a; Marotta 2008: 248).

Although the position of lexical stress in Athenian Greek is confined to one of the last three syllables of a word, it is less predictable than in the other three languages described here (Joseph and Warburton 1987; Revithiadou 1999; Arvaniti 2000). Also, unlike Maltese (see below), its position is not regulated by weight distinctions. Acoustically, stressed syllables are longer in duration and/or louder than unstressed ones (Arvaniti 1991, 2000). Moreover, according to recent studies (Fourakis et al. 1999; Nicolaidis 2003; Baltazani 2007a; Baltazani et al. 2014; Kainada and Baltazani 2014; Baltazani and Kainada 2015), unstressed syllables are spectrally reduced. There is as yet no consensus as to whether Greek has post-lexical rhythmic stress (Nespor and Vogel 1989; Kabak and Revithiadou 2009) or not (Arvaniti 1992, 1994; Kastrinaki 2003). Typically, there is one primary stress per content word but a secondary stress occurs on the final syllable of a content word with antepenultimate stress if it is followed by enclitics (Arvaniti 1992; Arvaniti and Baltazani 2005). In (2), the word po'ðilato, with antepenultimate stress, acquires a 
secondary stress when followed by the possessive $m u(2 \mathrm{~b})$, while treno with penultimate stress does not (2a). In such cases, the enclitic stress becomes primary in the prosodic word, while the original stress is demoted to secondary stress (Botinis 1989; Arvaniti 1992).

(2)

\section{a. /to 'treno $\mathrm{mu} / \rightarrow[$ to'trenomu $]$ the train my 'my train' \\ b. /to po'ðilato $\mathrm{mu} / \rightarrow$ [to po, ðila'tomu] the bike my 'my bike'}

(p. 238) An extensive analysis of stress in Greek varieties other than Athenian is still missing, though it has been proposed that in some northern varieties stress may occur in the pre-antepenultimate syllable of prosodic words (e.g. Newton 1972; Kontosopoulos 1994/ 2001).

In Maltese, stress is governed by syllable weight (Borg and Azzopardi-Alexander 1997; Vella 2009a), though it tends to surface frequently in penultimate position, as in Italian. Three rhyme types have been recognized: light (V), heavy (VC or VV), and superheavy (VCC or VVC). ${ }^{3}$ Stress falls on the heavy or superheavy syllable closest to the right edge of the word if such a syllable is present. Open final syllables must be heavy to be stressed; closed final syllables can only be stressed if they are superheavy. Interestingly, monosyllabic VC rhymes (as compared to VVC and VCC) are non-existent in Maltese (so min 'who' /mi:n/ and minn 'from' /min:/ but not /*mm/), indicating the existence of a minimality constraint at the level of the prosodic word. Antepenultimate stress in Maltese, noted as early as Sutcliffe (1936), was originally dismissed by Aquilina (1959: 73) as a 'foreign-stress pattern'. The penultimate vowel in loanwords into Maltese from Italian was often deleted, leading to forms with nativized penultimate stress (e.g. antipatiku It. antipatico 'unpleasant', giving /entı'pe:tko/). Many lexical items (e.g. pe'riklu 'danger', 'stonku 'stomach') and place names (e.g. 'Napli 'Naples', 'Tripli 'Tripoli') underwent this process of nativization involving lexicalization with one less syllable and penultimate stress (but note mużika /'mu:.zi.ke/ rather than *mużka /'mu:zke/ It. musica 'music' since the antepenultimate syllable in this case is heavy in its own right). In words without any heavy syllable, stress is assigned to the penultimate regardless of segmental composition.

French is the only language in this group with fixed, phrasal stress-that is, not specified at the lexical level (e.g. Coustenoble and Armstrong 1934: 4; see next paragraph for the relevance of foot structure). Primary stress is generally located on the last full syllable of the prosodic word (Dell 1984) immediately preceding the accentual phrase $(\alpha)$ right edge (Jun and Fougeron 2000, 2002; Michelas and D'Imperio 2012b), roughly equivalent to the phonological phrase $(\varphi)$ (Nespor and Vogel 1986; Post 2000a, 2000b) and the prosodic phrase of Di Cristo and Hirst (1993). Within the autosegmental-metrical framework (AM), 


\section{Southern Europe}

primary stress is marked by a pitch accent, a LH* rise in non-final, declarative $\alpha$ 's (Jun and Fougeron 2002). Secondary stress can also appear at the left edge of the $\alpha$ (as a $\mathrm{H}^{*}$ ) according to Post (2000a), though recent studies have analysed this event as a left-edge tonal specification for the $\alpha$ (i.e. LHr), which is accompanied by initial edge-strengthening with specific onset lengthening properties (Portes et al. 2012) and no rhyme lengthening (D'Imperio et al. 2007b).

At the foot level, French has been described as having an iambic structure (e.g. Plénat 1984; Hayes 1995; Andreassen and Eychenne 2013), although the realization of word-final schwa particularly in southern varieties (e.g. galette 'cake' /ga'letə/ vs. the standard form /ga'let/; Selkirk 1977; Coquillon et al. 2000; Turcsan 2005) has given rise to trochaic accounts (e.g. Selkirk 1978; Durand 1986). Word-initial and word-medial schwas are also found in southern varieties, though schwa is more marked depending on the variety and position in the (p. 239) word (/səmenə/ semaine 'week': Durand and Tarrier 2003; /letəьi/ laiterie 'milk factory': D'Imperio et al. 2015). Schwa occurrence is more restricted in northern and central varieties of French (Bürki et al. 2010, 2011; see e.g. Dell 1984 for an analysis). Schwa insertion in Italian is found in loanword-final position, mainly as a repair strategy to a phonotactic constraints violation, with variable outcomes (Lepschy and Lepschy 1981, and Bertinetto 1985 report it mainly in central and southern varieties). More recently, the complex nature of factors affecting schwa insertion in loanword-final position has been pointed out, such as its being conditioned by intonation (Grice et al. 2018).

\subsubsection{Rhythm}

The rhythm of Italian, French, and Greek was described as syllable-timed in earlier studies (Abercrombie 1967; Bertinetto 1981). However, acoustic analyses have cast doubt on the isochrony classification. For example, acoustic investigations have disputed the identification of Italian as syllable-timed (Vayra et al. 1984; Marotta 1985), demonstrating that expected clear-cut differences between syllable and stress-timed languages are not systematically found in connected speech (Roach 1982; see also chapter 11). Although the use of different metrics to characterize rhythmic structures (e.g. Grabe and Low 2002; Ramus 2002; Bertinetto and Bertini 2008; Bertini and Bertinetto 2009) may affect the results of language classification based on rhythmic features (see Mairano and Romano 2011), these metrics nevertheless suggest that Italian as well as other languages, including French and Greek, differ in their rhythmic characteristics in a continuous rather than a categorical way. They may even show cross-variety differences (Romito and Trumper 1989; Trumper et al. 1991; Schmid 2004; for Italian see also Giordano 2008 and Romano et al. 2010; for Canadian French see Boudreault 1968 and Cichocki et al. 2013).

Claims about Greek rhythm are particularly inconclusive, regardless of the metric used (Ramus et al. 1999; Grabe and Low 2002). While Dauer (1983) placed Greek in the syllable-timed category, Dauer (1987) argues against classifications based on syllable durations. Grabe and Low (2002) conclude that Greek is unclassifiable, while Baltazani 


\section{Southern Europe}

(2007a) suggests that it has a mixed rhythm, with greater consonantal than vocalic variability, in contrast to Ross et al. (2008) (see Arvaniti 2007 for details).

Finally, while vowel reduction of the sort occurring in English and German is absent in Maltese (as well as in Maltese English; see Vella 1995; Grech 2015), there are no further studies that allow for a characterization of its rhythm.

\subsubsection{Prosodic constituency}

The intermediate phrase (ip) and intonation phrase (IP, also $\mathrm{l}$ ) are part of the grammar of all four languages examined here. There is also evidence for a lower phrasing level, the accentual phrase $(\alpha)$, in French and Neapolitan Italian.

In Italian, external sandhi phenomena may signal phrase-internal cohesion, like Synaloephe and Raddoppiamento Fonosintattico in central and southern varieties (Marotta 1985; Nespor and Vogel 1986; Salza et al. 1988; Loporcaro 1997), which are usually (p. 240) absent at higher-level prosodic boundaries (D’Imperio and Gili Fivela 2003). The Italian IP may be signalled by final boundary tones (see §16.3.1), pre-boundary lengthening marking its right edge (D'Imperio 2002; D'Imperio and Gili Fivela 2003; Grice et al. 2005b), and possibly a pause. For Neapolitan Italian, D'Imperio et al. (2005) report a continuation rise or sustained pitch at the end of non-final ip's, arguably due to $\mathrm{H}-$, as in the case of long subject NPs in SVO declaratives. Gradient pre-boundary lengthening (and initial strengthening) has been found in acoustic and articulatory research (Gili Fivela et al. 2008; Petrone et al. 2010, 2014). Initial boundary tones have been proposed for specific functions, such as exclamatives (Gili Fivela et al. 2015a).

Italian ip-structure appears to reflect syntactic branchingness and specific syntactic constructions, rather than constituent weight, as is the case in other Romance languages. Consequently, ip boundaries can disambiguate syntactic attachments of prepositional and adverbial phrases, restrictive versus non-restrictive relative clauses, signal cleft sentences, left-dislocation of subjects and objects, right-dislocation, and vocative tags (Avesani 1990; Hirschberg and Avesani 2000; Gili Fivela 2008; Crocco 2013) as well as branchingness (D’Imperio et al. 2005).

Prosodic constituents appear to behave consistently across Italian varieties, for instance showing a similar amount of lengthening of the pre-boundary vowel (D'Imperio and Gili Fivela 2003). There is also evidence for an $\alpha$ in Neapolitan Italian (D'Imperio and Petrone 2008; Petrone and D'Imperio 2008), where an f0 inflection point between consecutive pitch accents has been identified as an $\alpha$-marking tone. Nespor (1993), too, proposes that each phonological word (similar to the $\alpha$ ) is marked by a right-edge tonal boundary in Standard Italian.

In Athenian Greek, the existence of the ip and IP is supported by tonal alignment and preboundary lengthening. Phrase accents demarcate the edges of ip's with simple tonal movements, while the boundary tones at the edges of IP's show more complex movements (e.g. for the rise-fall of YES/NO questions see Arvaniti et al. 2006b; Baltazani 
2007b) as well as higher H-scaling for the IP than for the ip edge tone (Arvaniti and Baltazani 2005; Kainada 2014). In addition, several sandhi phenomena are regulated in a gradient manner by boundary strength: for example, a smaller degree of post-nasal stop voicing occurs around the stronger boundary (Kainada 2010) and the likelihood of vowel assimilation in external hiatus VV sequences is much lower (Baltazani 2006; Kainada 2010). Greater pre-boundary lengthening is found before stronger boundaries in both Athenian (Kainada 2012) and Cypriot Greek (Themistocleous 2014), varieties that differ in the alignment of phrase accents (Arvaniti 1998). The status of the ip in varieties of Greek is still unsettled. No ip is assumed in the analysis of Corfiot Greek YES/NO questions, for instance, where the complex utterance-final pitch movements are argued instead to be the reflexes of bitonal or tritonal boundary tones (Giakoumelou and Papazachariou 2013).

Vella (1995) posited a $\varphi$-level in Maltese, equivalent to the ip, facilitating an account of postnuclear accents that follow and are dependent on the nuclear pitch accent within the same IP. Arguably, the ip can be dispensed with by adopting the notion of secondary association to stressed syllables for postnuclear tones (Pierrehumbert and Beckman 1988; Grice et al. 2000).

French clearly shows the existence of three levels of phrasing. Apart from the IP and the ip (Michelas 2011; Michelas and D'Imperio 2012b; D'Imperio and Michelas 2014), the existence of an $\alpha$, roughly corresponding to the phonological word, or the $\varphi$ of earlier approaches, is no longer questioned (e.g. Delais-Roussarie et al. 2015). The $\alpha$ is the domain of the LH* final rise in IP-internal position (Jun and Fougeron 1995, 2000, 2002) and of an optional initial LHı rise (for association specifications and frequency of occurrence in specific syntactic and (p. 241) information structure contexts see Welby 2006; Astésano et al. 2007; German and D'Imperio 2016). The different domains in the prosodic hierarchy are subject to differential pre-boundary lengthening (Michelas 2011; Michelas and D'Imperio 2012a, 2012b) and tonal alignment (D’Imperio et al. 2007a; Post 2011) as well as external sandhi phenomena such as liaison, enchainment (Morin and Kaye 1982; Clements and Keyser 1983; Prunet 1987; Encrevé 1988; Post 2000b; Fougeron 2007), and clash resolution (Verluyten 1982; Dell 1984; Selkirk 1986; Post 2000b). The ip is characterized by stronger pre-boundary lengthening than for $\alpha$ and by register manipulation attributable to a right-edge H- phrase accent (D’Imperio and Michelas 2014; see §16.3.2 for details). The ip also signals the morphosyntactic structure, guiding parsing and processing (Michelas and D'Imperio 2015). Finally, initial strengthening in $\alpha$-initial onsets helps to identify initial rises as an initial edge phenomenon, even though these are tonally similar to other kinds of rises (Portes et al. 2012).

\subsection{Intonation}

This section examines the main features of the intonational systems of the four languages. It includes overviews of their inventories and tonal patterns (§16.3.1), some aspects of the relationship between intonation and pragmatic meaning (\$16.3.2), and a number of phonological processes such as copying, merging, and truncation (§16.3.3). 


\section{Southern Europe}

The state of the art of the research is different for each language and crucially depends on the languages' overall sociolinguistic characteristics and the way investigators have addressed them.

Rather than a single spoken ideal standard, Italian shows a great deal of phonetic and phonological variation in its local instantiations. These largely reflect sociolinguistic variation arising in diglossic communities where both the official language and the local dialect are spoken (Berruto 1993). The knowledge we have about Italian intonation relates to analyses of its local varieties, phonetically described since the 1980s (e.g. Magno Caldognetto et al. 1978; Maturi 1988; for an overview of earlier studies, see Bertinetto and Magno Caldognetto 1993). In more recent work within the AM tradition, a rich set of pitch accent and boundary tone types has been reported for different varieties, such as those spoken in Naples (e.g. Caputo and D'Imperio 1995; Caputo 1996; D’Imperio 2002), Pisa (Gili Fivela 2004), Florence (Avesani 1990), Palermo (Grice 1995b), Bari (Grice and Savino 1995), Cosenza (Sorianello 2001), and Rome (Giordano 2006); Grice et al. (2005b) and Gili Fivela et al. (2015a) provide useful overviews. Below, we only describe the most commonly shared tendencies.

The essential characteristics of Standard French are well understood (see Delais-Roussarie et al. 2015 for a consensus transcription model), but authors have only recently started to investigate the specific intonational characteristics of its varieties, and hence only preliminary descriptions are available (e.g. Martin 2014; Simon 2012; as well as the comparative data used in Delais-Roussarie et al. 2015 for the varieties spoken in Fribourg, Geneva, Occitan Toulouse, Lacaune, Marseille, Paris, Orléans, Lille, and Louvainla-Neuve). Recent work has also covered Swiss French (Avanzi et al. 2012), Belgian French (Bardiaux et al. 2012), Occitan French (Sichel-Bazin et al. 2012), and Central African French (Bordal 2012).

Similarly to French, analyses of Greek intonation have mainly been based on the standard variety, which is Athenian Greek (GR_ToBI; Arvaniti and Baltazani 2005). However, a small number of studies on other Greek varieties have revealed phonological variation in pitch accent inventories (e.g. Baltazani and Kainada 2019 on Cretan Greek; Baltazani et al. 2019 on Asia Minor Greek), boundary tones (Arvaniti 1998 for Cypriot Greek; Papazachariou 1998, 2004 for Northern Greek; Giakoumelou and Papazachariou 2013 for Corfiot Greek), as well as phonetic variation on the tonal alignment of pitch accents (e.g. Baltazani and Kainada 2015 for Epirus Greek; Themistocleous 2016 for Cypriot).

Our knowledge of Maltese prosodic structure and intonation is mainly based on work on speakers whose dominant language is Maltese rather than (Maltese-)English (see Vella 2012). Following up on anecdotal references to differences in intonation between dialects in Gozo (Malta's sister island), as well as between these and dialects spoken in Malta (Aquilina 1965), Vella (2011a) provided evidence of a difference between Gozitan Żebbugi and Standard Maltese in the tonal alignment of the nuclear falling pitch accent. Research on the intonation of dialects of Maltese other than the standard is limited, however, and consequently the description provided below is limited to work on the standard variety. 


\subsubsection{Inventories}

As in other stress-accent languages, pitch accents mark metrical heads in Italian, though different varieties have different inventories of pitch accents and boundary tones. However, some patterns show homogeneous features, as in the case of broad-focus statements (H+L* L\%) (see Caputo 1996 and D'Imperio 2001, 2002 for the Neapolitan variety; Grice 1995b for Palermo Italian), WH-questions ( $\left.\mathrm{H}+\mathrm{L}^{*} \mathrm{~L} \%\right)$, counterexpectational WH-questions $\left(\mathrm{L}+{ }_{\mathrm{i}} \mathrm{H}^{*} \mathrm{H} \%\right)$, disjunctive questions $\left(\mathrm{H}+\mathrm{L}^{*} \mathrm{~L} \%\right.$ preceded by $\mathrm{L}+\mathrm{H}^{*}(\mathrm{H}-$ or $\mathrm{L}-)$ ), and vocatives ( $\mathrm{L}+\mathrm{H}^{*} \mathrm{H}$ !H; Gili Fivela et al. 2015a).

Note however that tonal pattern variation is diatopically pervasive in Italian (Grice et al. 2005b; Gili Fivela et al. 2015a). For example, no clear isogloss boundaries may be identified for YES/NO questions, for which there is no widely shared contour (see Gili Fivela and Nicora 2018: tab. 16.1; see also Savino 2012). Also, information-seeking questions may either (p. 243) be assigned various pitch accents and a rising terminal (e.g. in Milan, Pisa, Rome, and Bari) or may show a (rising-)falling contour (e.g. in Turin, Lucca, Naples, and Palermo). Furthermore, speakers of the same variety may use both falling and rising terminals (e.g. in Turin, La Spezia, Pisa, Bari, and Salerno; cf. Orrico et al. 2019).

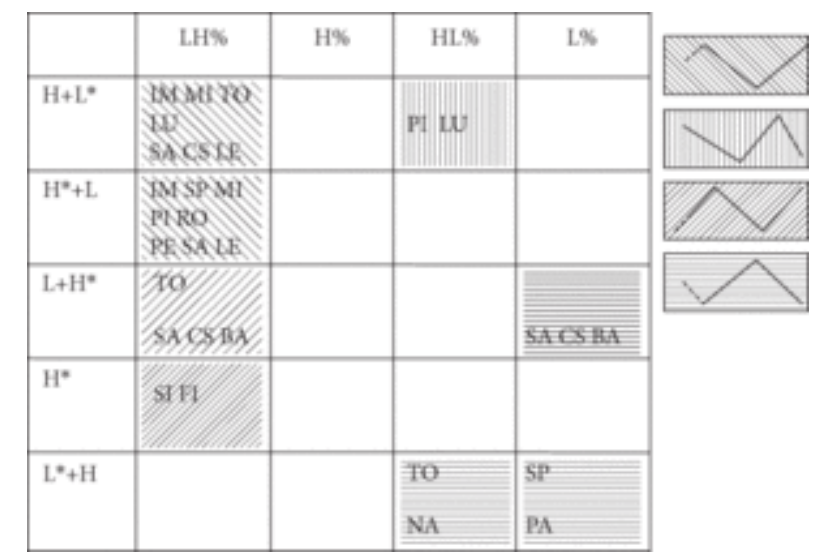

Table 16.1 Information-seeking yes/no questions: nuclear patterns in 16 Italian varieties (left table) and their stylization (right schemes); motifs indicate possible groupings on the basis of nuclear tunes; varieties are represented by abbreviations. For details see Gili Fivela and Nicora (2018), adapted and updated from Gili Fivela et al. (2015a)

$\mathrm{BA}=$ Bari; $\mathrm{CS}=$ Cosenza; $\mathrm{FI}=$ Florence; $\mathrm{IM}=$ Imperia; $\mathrm{LE}=$ Lecce; $\mathrm{LU}=$ Lucca; $\mathrm{MI}=$ Milan; $\mathrm{NA}=$ Naples; PA = Palermo; PE = Pescara; PI = Pisa; RO $=$ Rome; $\mathrm{SA}=$ Salerno; $\mathrm{SI}=$ Siena; $\mathrm{SP}=$ La Spezia; $\mathrm{TO}=$ Turin

Pitch accent alignment also depends on speech variety. The alignment of the sharp risefall, for instance, affects the identification of YES/NO questions and narrow-focus statements in Neapolitan Italian (D'Imperio and House 1997; D'Imperio 2000; Petrone 2008) and the alignment of a pitch accent rise signals YES/NO questions and exclamations in 


\section{Southern Europe}

Turin Italian (Gili Fivela et al. 2015b). The phonological status of alignment contrasts is in some cases debated. In Neapolitan, secondary association of the starred tones in $\mathrm{L}+\mathrm{H}^{*}$ and $\mathrm{L}^{*}+\mathrm{H}$ in YES/NO questions and narrow-focus statements has been proposed to the first mora of the accented syllable; in Pisa Italian, secondary association of $\mathrm{H}^{*}$ in continuation contours is proposed with the syllable's right boundary, and of $\mathrm{H}^{*}+\mathrm{L}$ pitch accent in contrastive-correction focus, with the first mora (Prieto et al. 2005). Secondary association to stressed syllables is also found for boundary tones in Florentine Italian postnuclear accents (Grice et al. 2005b), while the HL- phrase accent marking contrastive focus questions in Neapolitan is secondarily associated with the last stressed syllable of the focused constituent (D'Imperio 1999, 2001), forming an extended plateau for long constituents. More recently, tonal alignment regularities have been shown to be variable in individual speakers' production within the same regional variety (Niebuhr et al. 2011a), casting doubt on a discrete analysis of tonal alignment and its straightforward mapping to phonological form.

Various intonation models have been proposed for French (e.g. Hirst and Di Cristo 1998; Jun and Fougeron 2000, 2002; Post 2000a). The recent ToBI-like treatment of different varieties of French (Delais-Roussarie et al. 2015) is inspired by Post's and Jun and Fougeron's accounts. In Post's model, only two pitch accent types ( $\mathrm{H}^{*}$ and $\mathrm{H}+\mathrm{H}^{*}$ ) are included, with $\mathrm{L} \%$ and $\mathrm{H} \%$ for the IP left edge and the same edge tones plus a $0 \%$ (underspecified) boundary tone for the right edge. Phrase-medial L tones are modelled through a mechanism of L-insertion between $\mathrm{H}^{*}$ tones, and phonetic variants are derived through the spreading of tones and through downstep (\$16.3.2). For Jun and Fougeron (1995, $2000,2002)$, the basic unit of tonal organization in French is the $\alpha$, whose default underlying pattern is /LHıLH*/ characterized by an optional initial rise and an obligatory final rise (i.e. the obligatory element is $\mathrm{H}^{*}$ ). Five surface variants are predicted in this model (Figure 16.1), though the specific conditions for the appearance of each pattern are not explicitly stated. Note that the initial rise has also been modelled as an initial edge (p. 244) tone whose L target can show a secondary association with the left edge of the $\alpha$ (Welby 2003a, 2007).

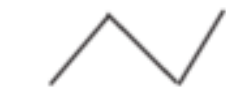

(a) $/ \mathrm{LHiLH}^{*} /$

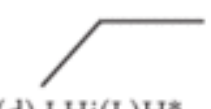

(d) $\mathrm{LHi}(\mathrm{L}) \mathrm{H}^{*}$

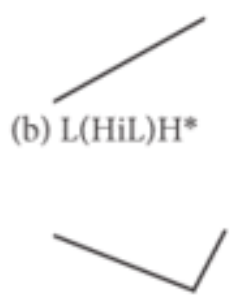

(e) (L)HiLH*
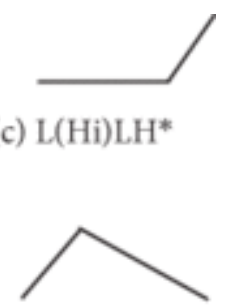

(f) $\mathrm{LHiL}^{*}$

Figure 16.1 Surface variants predicted by Jun and Fougeron's model (from Michelas and D'Imperio 2012b). 


\section{Southern Europe}

The tonal inventory of Athenian Greek (GR_ToBI; Arvaniti and Baltazani 2005) comprises six categories of pitch accent $\left(\mathrm{H}^{*}, \mathrm{~L}^{*}, \mathrm{~L}^{*}+\mathrm{H}, \mathrm{L}+\mathrm{H}^{*}, \mathrm{H}^{*}\right.$, and $\left.\mathrm{H}^{*}+\mathrm{L}\right)$, four categories of phrase accent (H-, L-, LH-, and !H-), and three boundary tones (H\%, L\%, and !H\%). Different combinations of phrase accents and boundary tones convey a number of pragmatic functions (Table 16.2). A small number of recent studies on other Greek varieties have revealed both phonological and phonetic variation (see the introduction to §16.3). A dual pattern in the alignment of the $\mathrm{H}$ - phrase accent has been found in Greek YES/NO questions, where the nucleus and the $\mathrm{H}$ - phrase accent both compete for alignment with the final stressed accent. The $\mathrm{H}$ - in general aligns with the final stressed syllable of the question unless the question nucleus associates with this syllable, in which case the $\mathrm{H}$ - is pushed rightwards to the right edge of the IP, where both the $\mathrm{H}$ - and the $\mathrm{L} \%$ are then realized together in a complex movement (Grice et al. 2000).

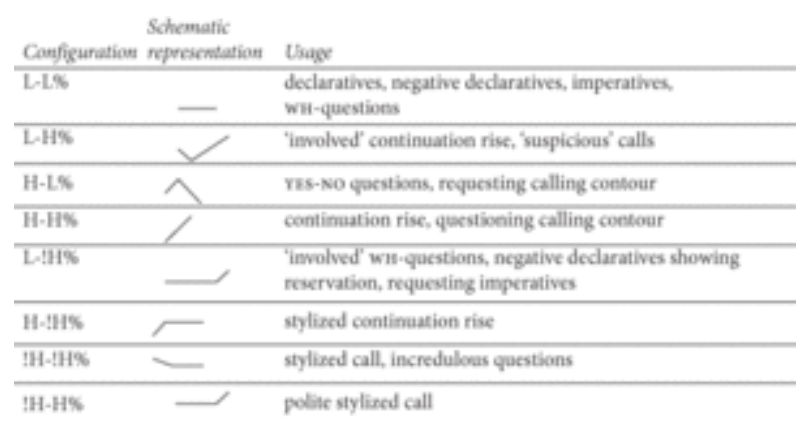

Table 16.2 Combinations of phrase accent and boundary tone and their pragmatic functions in Athenian Greek (from Arvaniti and Baltazani 2005).

Investigations into the regional variation of Greek intonation have revealed interesting patterns in the alignment of pitch accents. For example, the inventory of nuclear pitch accents of Cretan Greek declaratives has been found to include a $\mathrm{H}+\mathrm{L}^{*}$ contrasting with the $\mathrm{H}^{*}+\mathrm{L}$ nuclear pitch accent found in Athenian Greek (Baltazani and Kainada 2019), a difference that has been attributed to the long-term historical language contact between Cretan and Italian. Similar effects of language contact have been reported in a study comparing continuation rise melodies in the declaratives of Athenian, Asia Minor Greek, and Turkish. Baltazani et al. (2019) found that the continuation rise tune in Asia Minor Greek, $\mathrm{H}^{*}+\mathrm{L} \mathrm{H}$-, is similar to that in Turkish and different from the Athenian $\mathrm{L}^{*} \mathrm{H}$ - tune.

More fine-grained studies have shown phonetic variation in the details of tonal alignment in pitch accents. The Segmental Anchoring Hypothesis (SAH; Arvaniti and Ladd 1995; Arvaniti et al. 1998; Ladd et al. 1999; see D'Imperio 2006 for a discussion), formulated on the basis of evidence from the $\mathrm{L}^{*}+\mathrm{H}$ pitch accent in Athenian Greek, refers to the independent (p. 245) docking of the L and $\mathrm{H}$ onto specific segmental landmarks, contrary to traditional assumptions that the distance between a starred tone and its leading or trailing tone is stable (e.g. Pierrehumbert 1980: 44). Further support for the SAH is provided in the account of stable segmental anchoring reported in the northern dialect of Epirus Greek for $\mathrm{L}^{*}+\mathrm{H}$ (Baltazani and Kainada 2015). When the rule of unstressed high vowel 


\section{Southern Europe}

deletion in this dialect deprives the $\mathrm{H}$ tone of its typical anchor (the post-stressed vowel), the $\mathrm{H}$ peak aligns with the immediately preceding tautosyllabic consonant.

Note that although this hypothesis has also been corroborated by findings for British and American English (e.g. Ladd et al. 1999; Dilley et al. 2005), much more work is needed to examine its applicability. First, there have been recent proposals of a looser definition of segmental anchoring. The notion of 'anchorage', proposed for French by Welby and Lœevenbruck (2006), was corroborated by Themistocleous (2016), who reported evidence from Cypriot Greek, where the peak of the $\mathrm{L}^{*}+\mathrm{H}$ accent was found to align within a specific stretch of segmental material that is bigger than a single syllable. Second, and more importantly, the SAH has been called into question by work on Catalan, Dutch, English (see D'Imperio 2006 for a review), Neapolitan, Pisa and Bari Italian (D’Imperio 2000; Gili Fivela and Savino 2003; Petrone 2008), and Spanish (Prieto et al. 2010), showing that syllable structure is one of the factors that can alter tonal alignment. More recently, Petrone and D'Imperio (2015) have shown that such subtle alignment differences interact with syllable structure in the perception of both geminate versus singleton and question/ statement distinction in Neapolitan. These results show the importance of cross-linguistic and cross-dialectal research for the proper understanding of alignment mechanisms and the source of their variability.

Maltese pitch accents are primarily associated with the head of [+focus] material of the last $\varphi$ (equivalent to the ip in other accounts) within an IP. Phrase accents usually occur as a consequence of secondary association with the head of post-focal material within the same IP (but outside the scope of the ip). Boundary tones occur at the right edges of the phrases with which they are associated. Research on the intonation of WH-questions suggests the existence of left-edge tones in Maltese: the exact nature of the domain that serves as the edge is subject to ongoing investigation (see Grice et al. 2019). Two nuclear configurations comprising a pitch accent plus a boundary tone sequence (i.e. a falling $\mathrm{H}^{*}+\mathrm{L} \mathrm{L} \varphi$ and a rising $\mathrm{L}^{*} \mathrm{H} \varphi$ ) have been identified, in addition to two postnuclear, post-focal tonal sequences comprising a phrase accent and a boundary tone ( $\mathrm{L}^{-} \mathrm{H}$ and $\mathrm{L}^{+} \mathrm{H}^{-} \mathrm{Hr}$ ). The $\mathrm{L}^{-} \mathrm{H}$ tune always follows the falling nuclear tonal sequence, and $\mathrm{L}+\mathrm{H}^{-} \mathrm{H}$ the rising one (Vella 2003). Although the latter are stress seeking, similar to regular pitch accents, phrase accents in postnuclear tonal sequences appear to have a backgrounding function. Vella (1995), Magro (2004), and Vella (2007, 2011b) identified an additional falling tune with an exceptionally high starting point aligned before the stressed syllable, which continues to fall to the end of the phrase. The tune was first observed in vocatives and imperatives (Vella 1995) but has been more thoroughly investigated in WH-questions (Vella $2007,2011 b)$. A tentative analysis of the early $\mathrm{H}$ tone of the tune as being a left-edged (thus a $\mathrm{Hi} \mathrm{L}^{*} \mathrm{Li}$ ) tune has been proposed (though see more recently the analysis proposed in Grice et al. 2019).

In summary, the inventory of tonal sequences available to Maltese speakers described to date includes two nuclear pitch accent and boundary tone sequences $\left(\mathrm{H}+\mathrm{L}^{*} \mathrm{~L} \varphi\right.$ and $\mathrm{L}^{*}$ $\mathrm{H} \varphi$ ), prototypically used in statements and YES/NO questions respectively, and two postnuclear phrase accent and boundary tone sequences $\left(\mathrm{L}^{-} \mathrm{H \imath}\right.$ and $\mathrm{L}^{+} \mathrm{H}^{-} \mathrm{H \imath}$ ). The postnu- 
clear tunes (p. 246) are dependent on the preceding nuclear tune and can only occur in sequence with the relevant choice from among the former (so $\mathrm{H}+\mathrm{L}^{*} \mathrm{~L} \varphi$ is followed by $\mathrm{L}^{-} \mathrm{Hz}$ and $\mathrm{L}^{*} \mathrm{H} \varphi$ is followed by $\left.\mathrm{L}+\mathrm{H}^{-}\right)$. A tune described as $\mathrm{H} \imath \mathrm{L}^{*} \mathrm{Li}$ tune is also used in WH-questions, vocatives, and imperatives, among others (though, once again, see Grice et al. 2019).

\subsubsection{Downstep}

Register manipulation in the form of downstep similar to Germanic languages (e.g. Grice et al. 2005a for German; Beckman and Elam 1997 for English) is found in all four languages, although it serves different purposes in each language, as explained below.

Downstep in Italian is found in postnuclear position (e.g. $\mathrm{L}+\mathrm{H}^{*}$ and $\mathrm{L}^{*}+\mathrm{H}$ in Bari and Palermo Italian YES/NO questions; Grice et al. 2005b). In Neapolitan, an intrinsically downstepped pitch accent has also been proposed for the prototypical broad-focus nuclear accent !H+L* (D'Imperio 2002). In Neapolitan partial topic constructions of NP-VP sentences, the register of the prosodic phrase associated with the VP is globally downstepped (as (p. 247) described by van den Berg et al. 1992) only when it immediately follows a contrastive topic NP phrase (Figure 16.2), but not in non-contrastive constructions (D'Imperio et al. 2008; D'Imperio and Cangemi 2009; Brunetti et al. 2010). When the phrase break is not present, the pitch accents produced within the VP are higher than when the VP follows a partial topic phrase. This type of register downstep is not to be confused with the register compression caused by early, contrastive focus (on the sentence-initial NP). 


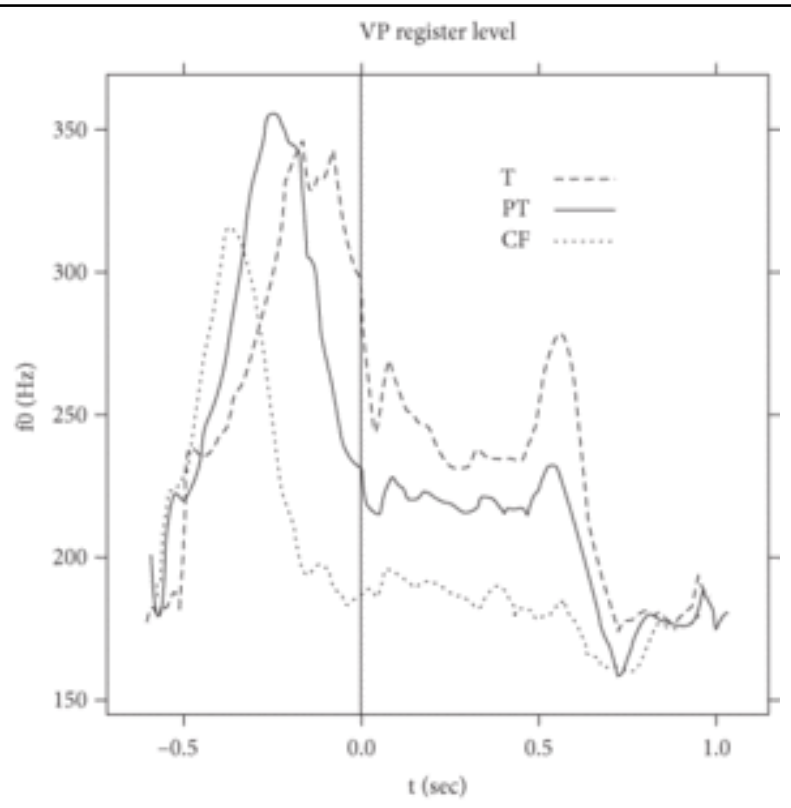

Figure 16.2 Pitch tracks for non-contrastive topic (T), partial topic (PT), and contrastive focus (CF) renditions of the sentence Milena lo vuole amaro 'Milena drinks it black', in Neapolitan (NP-VP boundary = vertical line).

(Data taken from D’Imperio and Cangemi 2009)

In Italian, similarly to other Romance languages (see chapter 16), downstep also affects boundary tones, particularly in vocatives: the 'vocative chant' signals initial calls and, quite often, insistent calls are realized as L+H* H!H\% (Gili Fivela et al. 2015a).

French register-level phenomena have recently been observed, providing support for the presence of an ip in the system. French is a 'head/edge prominence language' (Jun 2014b: 521), characterized by marking of initial and final edges (see §16.3.1) of tonal constituents, with prominence being restricted to final $\alpha$ position. The French ip is marked by a return to the register line ('total reset') determined by the first $\mathrm{H}^{*}$ peak within the IP, as seen in Figure 16.3 (D'Imperio and Michelas 2014). This internal 'reset' appears at an IPinternal right edge (hence in non-final ip's), usually marking a major syntactic boundary, blocking the iterative downstep reported in Post (2000a; see also Delais-Roussarie et al. 2011). Note that this phenomenon is reminiscent of the 'final upstep' rise described for German IP right edges (Truckenbrodt 2002), though in French the rise is the result of a H- phrase accent marking (p. 248) the right boundary of internal ip's (see H3 in Figure 16.3). The presence of a $H-$, as opposed to an $\alpha$-final rise, is also relevant in predicting morphosyntactic structure in French (Michelas and D'Imperio 2012a, 2012b, 2015). 


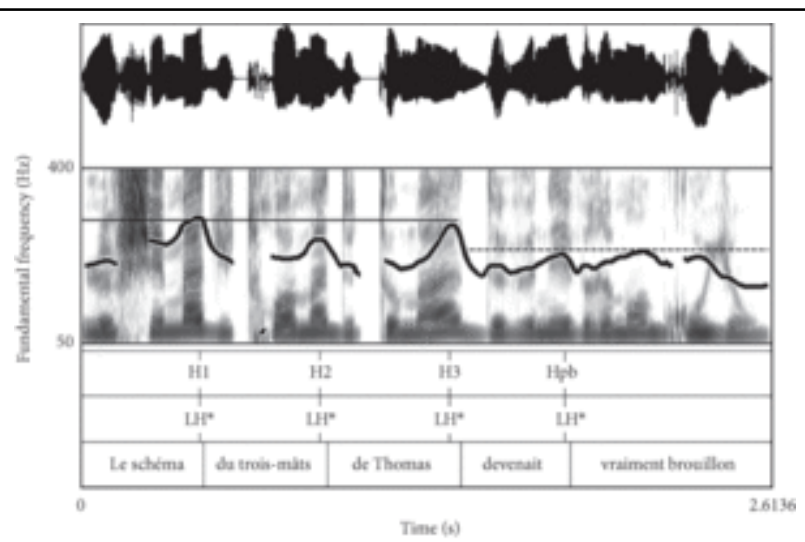

Figure 16.3 In the utterance Le schéma du troismâts de Thomas devenait vraiment brouillon 'Thomas's sketch of a square-rigger became a real scribble', the continuous line represents the reference pitch level for the first phrase.

(From D’Imperio and Michelas 2014)

Downstep in Greek is not triggered by tonal context. On the one hand, there are tunes ending in $\mathrm{L}$ - followed by a $\mathrm{H} \%$ that is not downstepped as well as tunes ending in $\mathrm{H}$ - followed by a L\% that is not upstepped (Baltazani and Jun 1999; Arvaniti and Baltazani 2005). On the other hand, there is evidence from WH-questions for a mid-level !H\% boundary tone that is stable in scaling and is not the result of phonetic adjustments. In fact, this choice of tone carries meaning and has been argued to be part of the Greek phonological inventory (Arvaniti et al. 2014). Recent work has revealed that downstep can be used in Athenian Greek to signal the difference between string identical declaratives and YES/NO questions, which differ in the realization of their prenuclear $\mathrm{L}^{*}+\mathrm{H}$ pitch accents: downstep between consecutive $\mathrm{L}^{*}+\mathrm{H}$ pitch accents has been found for YES/NO questions, while no such strategy is employed for statements (Baltazani et al. 2015).

With respect to downstepping and/or upstepping in Maltese, Vella (1995) describes the behaviour, in particular, of the postnuclear $\mathrm{L}+\mathrm{H}-\mathrm{H \imath}$, when this follows a nuclear $\mathrm{L}^{*} \mathrm{H} \varphi$ (Figure 16.4).

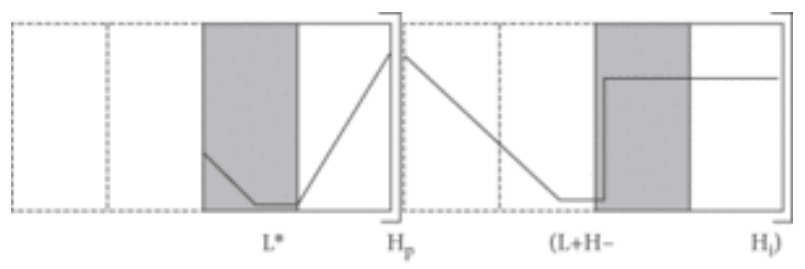

Figure 16.4 Schematization involving a nuclear L* $\mathrm{H} \varphi$ followed by a postnuclear $\mathrm{L}+\mathrm{H}-\mathrm{H}$ combination. 
Realization of an actual $\mathrm{L}$ tone preceding the $\mathrm{H}$ tone in the $\mathrm{L}+\mathrm{H}-$ phrase accent part of a $\mathrm{L}^{*} \mathrm{Hp} \mathrm{L}+\mathrm{H}-\mathrm{Hr}$ sequence is often dependent on the presence of sufficient segmental material. In other words, unless there is an intervening syllable between the nuclear and postnuclear stressed syllables, the sequence is likely to be realized as $\mathrm{L}^{*} \mathrm{Hp}$ ( ) H- Hu. Irrespective of whether the $\mathrm{L}$ tone in the phrase accent is present, both $\mathrm{H}$ tones in the $\mathrm{H}-\mathrm{Hz}$ sequence, when compared to the earlier $\mathrm{H} \varphi$, are scaled at a mid-level. An upstep rule along the lines proposed by Pierrehumbert (1980) has been suggested by Vella (1995) in view of the intervening $\mathrm{L}$ element in the $\mathrm{L}+\mathrm{H}-\mathrm{H}$.

In sum, the evidence presented in this section suggests that the mechanisms and use of downstep are language-specific and should be examined on that basis.

\subsubsection{Copying, merging, and truncation}

Among the processes of tonal copying, merging, truncation, compression, and tone spreading, truncation and compression are the ones most commonly found in the languages examined here.

In Palermo and Bari Italian, pitch accents copied onto the following phrase are found in YES/NO questions (Grice et al. 2005b); in Pisa Italian early focus YES/NO questions, both the pitch accent and the following phrase accent are copied onto the postnuclear phrase (Gili Fivela 2008). A tonal copy with a reduced range has also been noted for post-focal accents in Neapolitan questions (D’Imperio 2002).

(p. 249) Tonal copy is assumed to account for postnuclear pitch in early focus conditions in French (Jun and Fougeron 2000) and also in constructions with a post-posed theme or topic (Di Cristo 2000) and right-dislocated phrases (Dell 1984; Wunderli 1987; Ladd 1996). In Ladd's analysis (Figure 16.5), the pitch level of the right-dislocated constituent (Mercier) continues at the level reached after the pitch accent fall on argent.

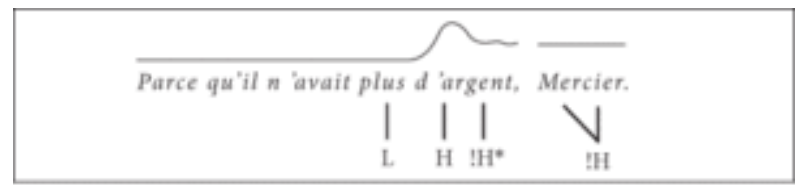

Figure 16.5 Tonal copy of the final tone of the matrix sentence Parce qu'il n'avait plus d'argent 'Because he didn't have any money' onto the right-dislocated constituent Mercier (after Ladd 1996: 141-142).

Substantial evidence for tonal copying is available for Maltese (Vella 2003; Cremona et al. 2017) relating to the postnuclear tunes involving secondary association to elements following one of the two nuclear tunes, described in \$16.3.1. Empirical evidence suggests that a number of iterations are perfectly possible (see examples in Vella 2009b: 53-54). Tonal copying has also been reported in the stylized rises described by Cremona et al.'s 
work on politeness (one documented example involves five iterations: Cremona et al. 2017: 782).

In Neapolitan Italian one-word focus constituents of YES/NO questions, the $\mathrm{H}$ target of a focal $L^{*}+\mathrm{H}$ merges with the following HL- phrase accent (D'Imperio 1999, 2002). In Pescara Italian, merging is reported for various pitch accent combinations in one-word constituents (e.g. $\mathrm{L}+\mathrm{H}^{*}$ and the following $\mathrm{H}+\mathrm{L}^{*}$ in broad and narrow non-contrastive focus, or $\mathrm{H}^{*}+\mathrm{L}$ in narrow contrastive focus and YES/NO questions); in longer constituents, $\mathrm{H}^{*}$ tone spreading accounts for high sustained plateaux (Gili Fivela et al. 2015a). Some Italian varieties appear to belong to the truncation rather than the compression type. In Palermo Italian L*+H L-L\% YES/NO questions, the final L edge tone is usually truncated (Grice 1995b). However, partial and optional truncation are also reported. In Bari Italian, the former is found in $\mathrm{L}+\mathrm{H}^{*} \mathrm{~L}-\mathrm{L} \% \mathrm{YES} / \mathrm{NO}$ questions (Grice et al. 2005b), while tonal compression of the $\mathrm{L}+\mathrm{H}^{*} \mathrm{LH} \%$ sequence is observed in read speech (Grice et al. 1997; Refice et al. 1997). The latter is reported in Pisa Italian YES/NO questions, where speakers may either preserve or truncate the L\% target in (p. 250) H+L* HL\% (Gili Fivela 2008). However, recent findings on final schwa insertion in loanwords as a function of intonation (see Grice et al. 2018 on Bari Italian) may point to the existence of competing strategies for tune-text association in Italian varieties.

Though systematic work on the effects of tonal crowding on tone target realization is still lacking in Greek, there are reports of undershoot or elision of $L$ tones in $\mathrm{L}^{*}+\mathrm{H}$, as well as earlier or later $\mathrm{H}$ alignment, as a result of tonal crowding in Athenian (Arvaniti et al. $1998,2000)$. There are also reports of $H$ tone compression in $L^{*}+H$ as a result of segmental deletion in Epirus Greek (Baltazani and Kainada 2015).

In Maltese, tonal crowding occurs in IP-final (accentual or boundary) rises (Vella 2009b), which would appear to undergo compression rather than truncation (though note the discussion of the realization of the $\mathrm{L}$ in $\mathrm{L}+\mathrm{H}$ - above). The sing-song quality that Maltese has for many foreign listeners may well be related to an avoidance of truncation, in addition to a tendency towards the prolongation of segments at boundaries (Vella et al. 2016).

\subsection{Conclusion}

The four languages reviewed in this chapter neatly illustrate the wide range of variability that can be observed among Western European languages, even in the geographically constrained set considered here, as evidenced in their tonal inventories, the processes that operate on them, and their association and alignment with other levels of structure. At the same time, they also illustrate how typologically diverse languages can show quite a few commonalities, possibly partially due to areal proximity. 


\section{Notes:}

$\left({ }^{1}\right)$ We will generally treat the languages in this sequence: Italian, Greek, Maltese, and French. However, we will change the order in cases where some of the languages share commonalities.

${ }^{2}$ ) Italian varieties (local phonetic/phonological variants of the standard language) are different from Italian dialetti, which are the continuation of Latin as spoken in the different territories and are largely autonomous linguistic systems.

$\left(^{3}\right)$ VV indicates a long vowel or diphthong, and CC a cluster or geminate. Onsets are optional and neutral regarding stress assignment. They may contain two to four consonants depending on their position in the word (Borg and Azzopardi-Alexander 1997; Galea 2016).

\section{Mariapaola D'Imperio}

Mariapaola D'Imperio is currently Distinguished Professor in the Department of Linguistics and the Cognitive Science Center at Rutgers University and Head of the Speech and Prosody Lab. She obtained a PhD in linguistics from Ohio State University in 2000 and then joined the Centre National de la Recherche Scientifique in 2001. She then obtained a position as Professor of Phonetics, Phonology and Prosody at the Department of Linguistics at Aix-Marseille University, where she was Head of the Prosody Group at the Laboratoire Parole et Langage in Aix-en-Provence, France. She is currently associate editor of the Journal of Phonetics and president of the Association for Laboratory Phonology. Her research interests span the intonational phonology of Romance languages to prosody production, perception, and processing.

\section{Barbara Gili Fivela}

Barbara Gili Fivela is Associate Professor at the University of Salento, where she is also vice-director of the Centro di Ricerca Interdisciplinare sul Linguaggio and director of the programme for Studies in Interlinguistic Mediation/Translation and Interpretation. Since 2019, she has been president of the Associazione Italiana Scienze della Voce, an ISCA Special Interest Group. Her main research interests are the phonology and phonetics of intonation, second language learning processes, and the kinematics of healthy and dysarthric speech.

\section{Mary Baltazani}

Mary Baltazani is a researcher at the Phonetics Laboratory, University of Oxford. Her research focuses on phonetics, phonology, and their interface, with special interests in intonation and pragmatics, Greek dialects, dialectology, and sociophonetics. She is currently investigating the diachronic development of intonation as it has been shaped by the historical contact of Greek with Italian and Turkish in a project supported by the Economic and Social Research Council, UK. 


\section{Southern Europe}

\section{Brechtje Post}

Brechtje Post is Professor of Phonetics and Phonology at the University of Cambridge. Her research focuses on speech prosody, which she explores from a number of different angles (phonology, phonetics, acquisition, and cognitive and neural speech processing).

\section{Alexandra Vella}

Alexandra Vella completed her PhD in linguistics at the University of Edinburgh in 1995. She is Associate Professor of Linguistics at the University of Malta, where she coordinates the Sound component of the Institute of Linguistics and Language Technology programme, teaching various courses in phonetics and phonology. Her main research focus is on prosody and intonation in Maltese and its dialects, as well as Maltese English, the English of speakers of Maltese in the rich and complex linguistic context of Malta. She leads a small team of researchers working on developing annotated corpora of spoken Maltese and its dialects as well as of Maltese English. 